\title{
Trichloroisocyanuric Acid, a New and Efficient Catalyst for the Synthesis of 2'- Aminobenzothiazolo-arylmethyl-2-naphthols
}

\author{
LIMIN YANG \\ School of Pharmacy, Xinxiang Medical University \\ Xinxiang, Henan 453003, P. R. China \\ yanglimin1982@126.com
}

Received 27 August 2011; Accepted 04 October 2011

\begin{abstract}
An efficient one-pot synthesis of 2'-aminobenzothiazolo-arylmethyl2 -naphthols is described. This involves the three-component reaction of $\beta$-naphthol, aromatic aldehydes and 2-aminobenzothiazole in the presence of a catalytic amount of trichloroisocyanuric acid under solvent-free conditions.
\end{abstract}

Keywords: Aldehydes, $\beta$-Naphthol, 2-Aminobenzothiazole, Trichloroisocyanuric acid, Synthesis.

\section{Introduction}

Benzothiazoles are an important group of heterocyclic compounds. Several derivatives have been found to possess useful biological activities such as anti-inflammatory ${ }^{1}$, anti-tumour ${ }^{2}$, anticonvulsant $^{3}$, antibacterial ${ }^{4}$, antifungal ${ }^{5}$ and topoisomerase II inhibitory activities ${ }^{6}$. In addition, benzothiazoles are also useful synthetic intermediates that are prone to various transformations and transition-metal-catalyzed cross-coupling reactions, such as Heck ${ }^{7}$, Negishi $^{8}$, Stille $^{9}$ and Sonogashira couplings ${ }^{10}$.

As a result of their importance as substructures in a broad range of natural and designed products, significant effort continues to be directed toward the development of new benzothiazole-based structures and new methods for their construction. Recently, synthesis of 2'-aminobenzothiazolo-arylmethyl-2-naphthols have been reported using $\mathrm{LiCl}^{11}$ and [Hnmp] $\mathrm{HSO}_{4}{ }^{12}$ as catalysts. However, many of these methodologies suffer from one or more disadvantages such as requirement of excess or expensive catalysts, prolonged reaction time. Therefore, the development of mild, efficient, inexpensive and facile methods for the synthesis of 2'-aminobenzothiazolo- arylmethyl-2-naphthols is necessary part of organic synthesis.

Trichloroisocyanuric acid (TCCA), an inexpensive, easily available reagent, low toxicity and less corrosive, has been widely used in organic reactions ${ }^{13}$, but it has not been carefully studied as a catalyst in the synthesis of 2'-aminobenzo-thiazolo-arylmethyl-2naphthols until now. In continuation of our efforts to explore newer reactions for the synthesis of heterocyclic compounds ${ }^{14}$, we decided to explore the possibility of synthesizing 
2'-aminobenzo- thiazolo-arylmethyl-2- naphthols by one-pot, three-component condensation of $\beta$-naphthol, aromatic aldehydes and 2-aminobenzothiazole in the presence of a catalytic amount ofTCCA under solvent-free conditions (Scheme 1).

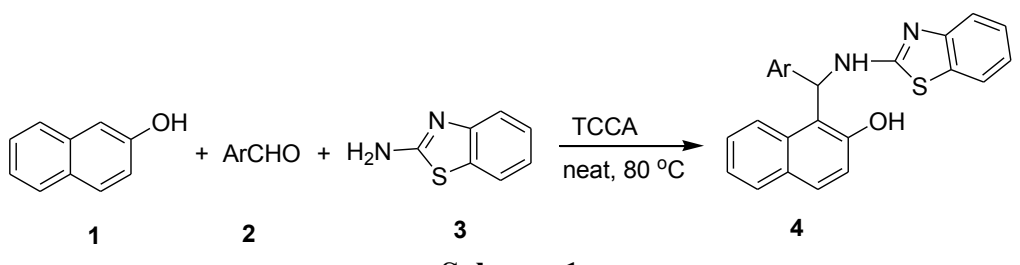

Scheme 1

\section{Experimental}

IR spectra were determined on FTS-40 infrared spectrometer; NMR spectra were recorded on Bruker AV-400 spectrometer at room temperature using TMS as an internal standard, coupling constants $(J)$ were measured in $\mathrm{Hz}$; Elemental analysis were performed by a Vario-III elemental analyzer; Melting points were determined on a XT-4 binocular microscope and were uncorrected; Commercially available reagents were used throughout without further purification unless otherwise stated.

General procedure for the preparation of 4

A mixture of the $\beta$-naphthol ( $1 \mathrm{mmol})$, aldehydes $(1 \mathrm{mmol}), 2$-aminobenzothiazole $(1 \mathrm{mmol})$, and TCCA $(0.1 \mathrm{mmol})$ was stirred at $80{ }^{\circ} \mathrm{C}$ for the appropriate time according to Table 2 . Completion of the reaction was indicated by TLC. The reaction was cooled to room temperature, washed with water, extracted with ethyl acetate $(3 \times 10 \mathrm{~mL})$. The combined organic layers were dried over sodium sulfate and concentrated under reduced pressure to afford a white powder. The pure solid products were obtained by recrystallization from ethanol.

\section{Spectral data of new products}

2'-Aminobenzothiazolo-(3-nitrophenyl)methyl-2-naphthol (4g)

IR (KBr): v 3335, 1627, 1597, 1541, 1531, 1452, 1436, 1347, 1312, 1270, 1252, 1210, 813, $753 \mathrm{~cm}^{-1}$; ${ }^{1} \mathrm{H}$ NMR (DMSO- $\left.d_{6}, 400 \mathrm{MHz}\right) \delta: 7.05-7.88(\mathrm{~m}, 15 \mathrm{H}, \mathrm{ArH}$ and $\mathrm{CH}), 8.90(\mathrm{~s}, 1 \mathrm{H}$, $\mathrm{NH}), 10.12(\mathrm{~s}, 1 \mathrm{H}, \mathrm{OH})$; Anal. calcd for $\mathrm{C}_{24} \mathrm{H}_{17} \mathrm{~N}_{3} \mathrm{O}_{3} \mathrm{~S}: \mathrm{C}$ 67.43, H 4.01, N 9.83, S 7.50; found C 67.50, H 4.00, N 9.87, S 7.42.

\section{2'-Aminobenzothiazolo-(3,4,5-trimethoxyphenyl)methyl-2-naphthol (4k)}

IR (KBr): v 3347, 2936, 2836, 2599, 1627, 1595, 1544, 1507, 1436, 1417, 1332, 1268, 1233 , $1129,1006,816,753 \mathrm{~cm}^{-1}$; ${ }^{1} \mathrm{H}$ NMR (DMSO-d $\left.6,400 \mathrm{MHz}\right) \delta: 3.58-3.64\left(\mathrm{~m}, 9 \mathrm{H}, \mathrm{OCH}_{3}\right.$ ), 6.80-7.81 (m, 13H, ArH and $\mathrm{CH}), 8.81(\mathrm{~s}, 1 \mathrm{H}, \mathrm{NH}), 10.15(\mathrm{~s}, 1 \mathrm{H}, \mathrm{OH})$; Anal. calcd for $\mathrm{C}_{27} \mathrm{H}_{24} \mathrm{~N}_{2} \mathrm{O}_{4} \mathrm{~S}$ : C 68.62, H 5.12, N 5.93, S 6.79; found C 68.70, H 5.04, N 6.00, S 6.82.

\section{Results and Discussion}

The model reaction of $\beta$-naphthol, benzaldehyde and 2-aminobenzothiazole was conducted to screen the optimal reaction conditions and the results were listed in Table I. First, the effect of temperature was tested. At $80^{\circ} \mathrm{C}$, the reaction proceeded smoothly and gave short reaction time and high yield. Therefore, we kept the reaction temperature at $80{ }^{\circ} \mathrm{C}$.

Moreover, we also studied influence of the amount of TCCA on the reaction yields. One $10 \mathrm{~mol} \%$ of TCCA was sufficient, excessive amount of catalyst did not increase the yield remarkably (Table 1, Entries 11-14). In light of these results, subsequent studies were carried 
out under the following optimized conditions, that is, with $10 \mathrm{~mol} \% \mathrm{TCCA}$ at $80{ }^{\circ} \mathrm{C}$ under solvent-free conditions.

Table 1. Synthesis of 2'-aminobenzothiazolo-phenylmethyl-2-naphthol under various conditions ${ }^{\mathrm{a}}$.

\begin{tabular}{ccccc}
\hline Entry & TCCA $/ \mathrm{mol} \%$ & Temp. $/{ }^{\circ} \mathrm{C}$ & Time $/ \mathrm{min}$ & Yield $/ \%^{\mathrm{b}}$ \\
\hline 1 & 0 & 100 & 90 & $<5$ \\
2 & 5 & 80 & 45 & 76 \\
3 & 5 & 100 & 30 & 81 \\
4 & 10 & 25 & 90 & 52 \\
5 & 10 & 50 & 60 & 63 \\
6 & $\mathbf{1 0}$ & 60 & 45 & 71 \\
7 & $\mathbf{1 0}$ & 70 & 30 & 85 \\
8 & $\mathbf{1 0}$ & 80 & 30 & 93 \\
9 & $\mathbf{1 0}$ & 90 & 20 & 93 \\
10 & $\mathbf{1 0}$ & 100 & 20 & 92 \\
11 & 15 & 70 & 30 & 86 \\
12 & 15 & 80 & 20 & 90 \\
13 & 20 & 80 & 20 & 92 \\
14 & 25 & 80 & 20 & 92 \\
\hline
\end{tabular}

${ }^{a}$ Reaction conditions: $\beta$-naphthol (1 mmol); benzaldehyde (1 mmol); 2-amino- benzothiazole (1 mmol); neat, ${ }^{b}$ Isolated yield.

Next stage, we studied the scope of reaction for the synthes of 2'-aminobenzothiazoloarylmethyl-2-naphthols from various aldehydes under optimized conditions (Table 2). A series of substituted aromatic aldehydes with electron-donating or electron-withdrawing groups attaching aromatic ring were investigated. Aromatic aldehydes with both the electron-withdrawing groups and the electron-releasing groups gave high yields of the desired products. The substituents on the ortho or opposite position have no obvious difference. Unfortunately, with aliphatic aldehydes, a mixture of products was obtained and the desired product could not been isolated.

Table 2. Preparation of 2'-aminobenzothiazolo-arylmethyl-2-naphthols ${ }^{\mathrm{a}}$.

\begin{tabular}{cccccc}
\hline Entry & $\mathrm{Ar}$ & Time/ min & Products & Yield $/ \%{ }^{\mathrm{b}}$ & m.p. (lit.) $/{ }^{\circ} \mathrm{C}$ \\
\hline 1 & $\mathrm{C}_{6} \mathrm{H}_{5}$ & 30 & $4 \mathrm{a}$ & 93 & $202-204(204-205)^{11}$ \\
2 & $4-\mathrm{Cl}-\mathrm{C}_{6} \mathrm{H}_{4}$ & 20 & $4 \mathrm{~b}$ & 96 & $209-210(209-210)^{11}$ \\
3 & $4-\mathrm{Me}-\mathrm{C}_{6} \mathrm{H}_{4}$ & 30 & $4 \mathrm{c}$ & 94 & $183-184(182-183)^{11}$ \\
4 & $4-\mathrm{F}-\mathrm{C}_{6} \mathrm{H}_{4}$ & 20 & $4 \mathrm{~d}$ & 97 & $189-190(188-189)^{12}$ \\
5 & $4-\mathrm{NO}_{2}-\mathrm{C}_{6} \mathrm{H}_{4}$ & 20 & $4 \mathrm{e}$ & 95 & $188-189(190-191)^{12}$ \\
6 & $4-\mathrm{MeO}^{12} \mathrm{C}_{6} \mathrm{H}_{4}$ & 30 & $4 \mathrm{f}$ & 92 & $172-173(175-176)^{12}$ \\
7 & $3-\mathrm{NO}_{2}-\mathrm{C}_{6} \mathrm{H}_{4}$ & 40 & $4 \mathrm{~g}$ & 90 & $197-199(198-199)^{11}$ \\
8 & $2-\mathrm{Cl}_{6} \mathrm{C}_{6} \mathrm{H}_{4}$ & 30 & $4 \mathrm{~h}$ & 92 & $185-186(189-190)^{12}$ \\
9 & $2,4-\mathrm{Cl}_{2}-\mathrm{C}_{6} \mathrm{H}_{3}$ & 40 & $4 \mathrm{i}$ & 95 & $203-204(206-207)^{12}$ \\
10 & $4-\mathrm{OH}-3-\mathrm{MeO}_{-}-\mathrm{C}_{6} \mathrm{H}_{3}$ & 40 & $4 \mathrm{j}$ & 89 & $192-194(194-195)^{12}$ \\
11 & $3,4,5-\mathrm{MeO}_{3} \mathrm{C}_{6} \mathrm{H}_{2}$ & 40 & $4 \mathrm{k}$ & 93 & $159-160$ \\
\hline
\end{tabular}

${ }^{a}$ Reaction conditions: $\beta$-naphthol (1 mmol); aldehyde (1 mmol); 2-amino- benzothiazole (1 mmol); TCCA (0.1 mmol); $80{ }^{\circ} \mathrm{C}$; neat, ${ }^{b}$ Isolated yield. 
Since TCCA contains chlorine atoms attached to nitrogen atoms, it is likely that it releases $\mathrm{Cl}^{+}$in situ, which acts as a catalyst in the reaction medium. Therefore, the mechanism shown in Scheme 2 can be suggested for this conversion.

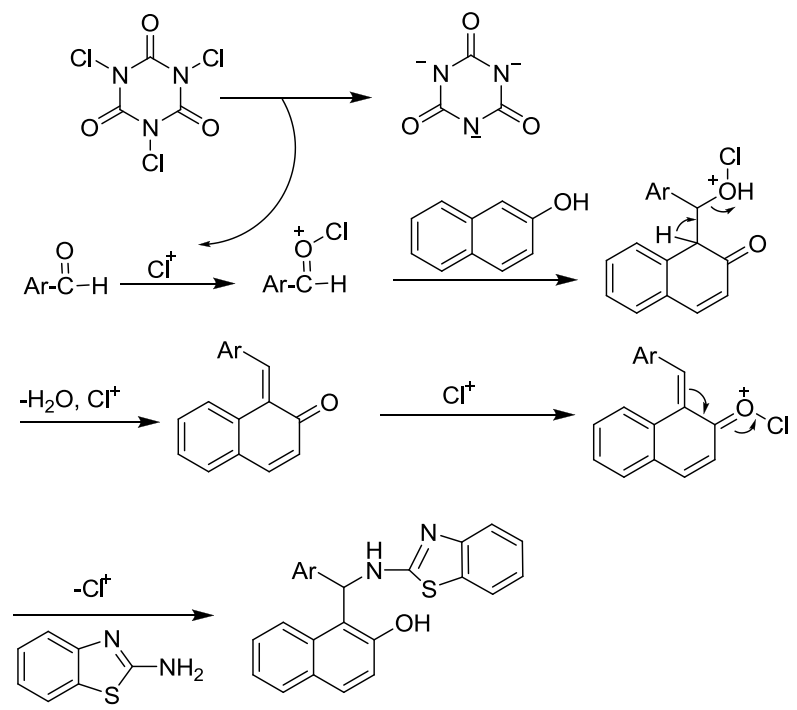

Scheme 2

\section{Conclusion}

In conclusion, we developed a new application for TCCA. By using this catalyst, a series of 2'-aminobenzothiazolo-arylmethyl-2-naphthols were obtained in high yields via threecomponent reaction of $\beta$-naphthol, aromatic aldehydes and 2-aminobenzothiazole under solvent-free conditions. Further applications of TCCA in organic transformation are currently in progress in our laboratories.

\section{Acknowledgment}

We are pleased to acknowledge the financial support from Xinxiang Medical University.

\section{Reference}

1. el-Shorbagi A N, Sakai S, el-Gendy M A, Omar N and Farag H H, Chem Pharm Bull., 1989, 37, 2971.

2. (a) Shi D F, Bradshaw T D, Wrigley S, McCall C J, Lelieveld P, Fichtner I and Stevens M F, J Med Chem., 1996, 39, 3375; (b) Wells G, Bradshaw T D, Diana P, Seaton A, Shi D F, Westwell A D and Stevens M F, Bioorg Med Chem Lett., 2000, 10, 513; (c) Hutchinson I, Chua M S, Browne H L, Trapani V, Bradshaw T D, Westwell A D and Stevens M F, J Med Chem., 2001, 44, 1446; (d) Racane L, Kralj M, Suman L, Stojkovic R, Tralic-Kulenovic V and Karminski-Zamola G, Bioorg Med Chem Lett., 2010, 18, 1038.

3. (a) Chopade R S, Bahekar R H, Khedekar P B, Bhusari K P and Rao A R R, Arch Pharm., 2002, 335, 381; (b) Amnerkar N D and Bhusari K P, Eur J Med Chem., 2010, 45, 149.

4. Palkar M, Noolvi M, Sankangoud R, Maddi V, Gadad A and Nargund L V G, Arch Pharm., 2010, 343, 353. 
5. Singh T, Srivastava V K, Saxena K K, Goel S L and Kumar A, Arch Pharm., 2006, 339, 466.

6. Choi S-J, Park H J, Lee S K, Kim S W, Han G and Choo H.-Y, Bioorg Med Chem., 2006, 14, 1229.

7. Aoyagi Y, Inoue A, Koizumi I, Hashimoto R, Tokunaga K, Gohma K, Komatsu J, Sekine K, Miyafuji A, Konoh J, Honma R, Akita Y and Ohta A, Heterocycles, 1992, 33, 257.

8. (a) Kosugi M, Koshiba M, Atoh A, Sano H and Migita T, Bull Chem Soc Jpn., 1986, 59, 677; (b) Birchler A G; Liu F and Liebeskind L S, J Org Chem., 1994, 59, 7737.

9. Nye S A and Potts K T, Synthesis, 1988, 375.

10. Gillet J.-P., Sauvetre R and Normant J-F, Tetrahedron Lett., 1985, 26, 3999.

11. Shaabani A, Rahmati A and Farhangi E, Tetrahedron Lett., 2007, 48, 7291.

12. Yu L and Guo H Y, Chin J Org Chem., 2011, 31, 96.

13. (a) Bigdeli M A, Jafari S, Mahdavinia G H and Hazarkhani H, Catal Commun., 2007, 8, 1641; (b) Bigdeli M A, Dostmohammadi H, Mahdavinia G H and Nemati F, $J$ Heterocycl Chem., 2008, 45, 1203; (c) Pore D M, Mahadik S M and Desai U V, Synth Commun., 2008, 38, 3121; (d) Bigdeli M A, Nemati F, Mahdavinia G H and Doostmohammadi H, Chin Chem Lett., 2009, 20, 1275; (e) Xu Y; Peng Y, Sun J, Chen J, Ding J and Wu H, J Chem Res., 2010, 34, 358; (f) Veisi H, Synthesis, 2010, 2631; (g) Pourali A R and Fatemi F, Chin Chem Lett., 2010, 21, 1283; (h) Veisi H, Gholbedaghi R, Malakootikhah J; Sedrpoushan A, Maleki B and Kordestani D, J Heterocycl Chem., 2010, 47, 1398.

14. (a) Wu L Q, Yang C G, Yang L M and Yang L J, Heterocycles, 2009, 78, 977; (b) Wu L Q; Yang L M, Yan F L, Yang C G and Fang L Z, Bull Kor Chem Soc., 2010, 31, 1051; (c) Wu L Q; Wu Y F, Yang C G, Yang L M and Yang L J, J Braz Chem Soc., 2010, 21, 941. 


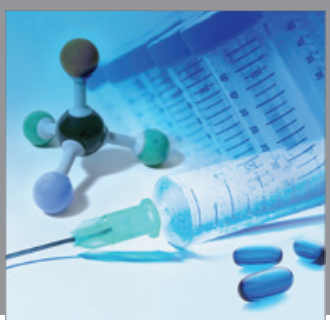

International Journal of

Medicinal Chemistry

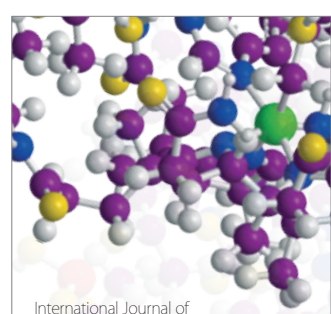

Carbohydrate Chemistry

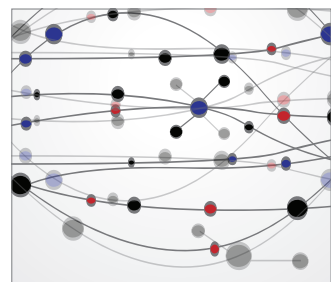

The Scientific World Journal
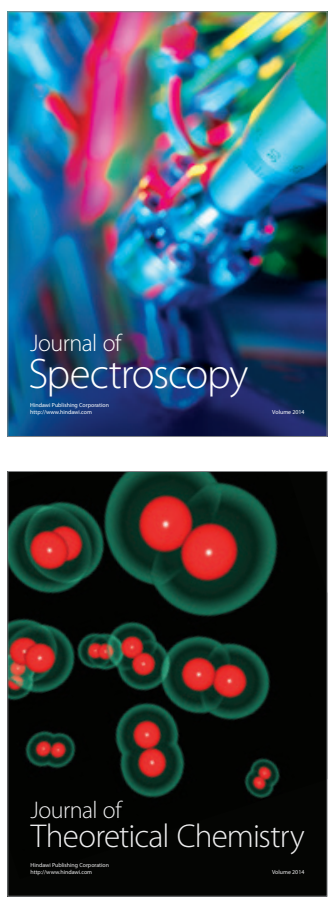
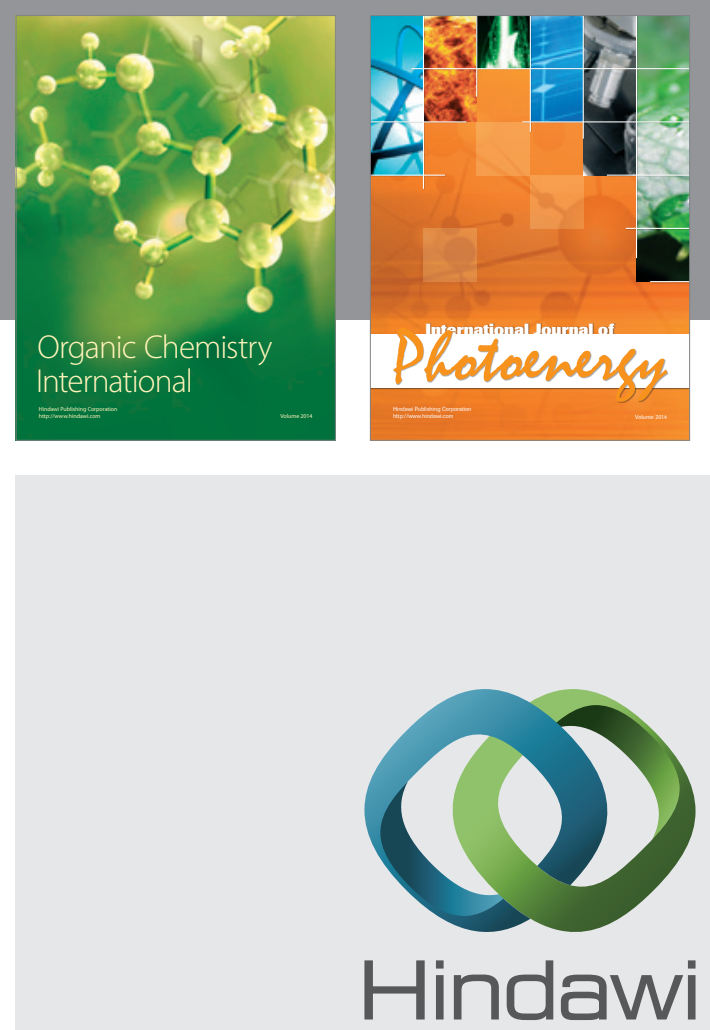

Submit your manuscripts at

http://www.hindawi.com
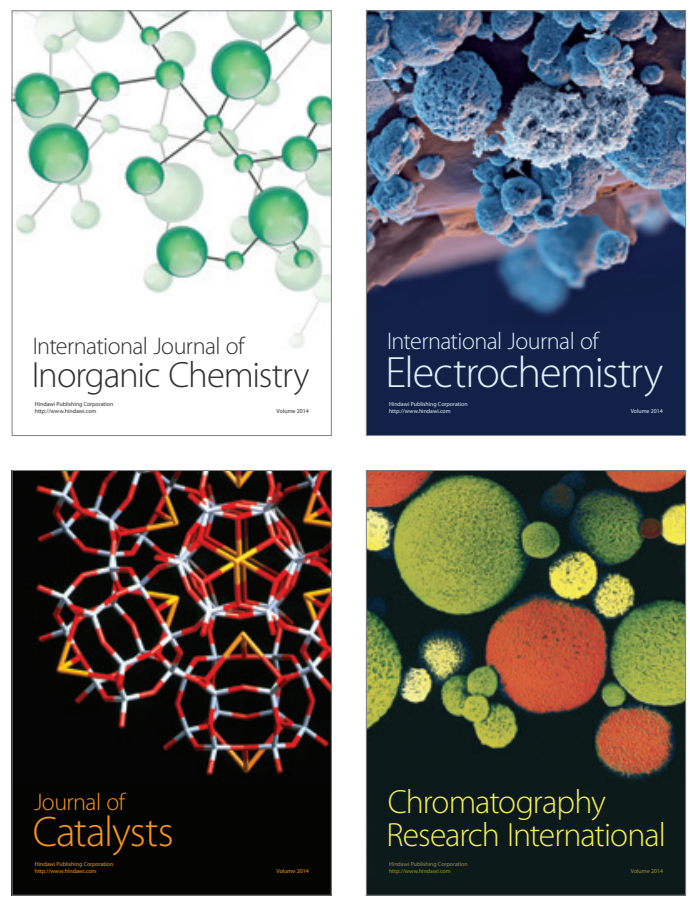
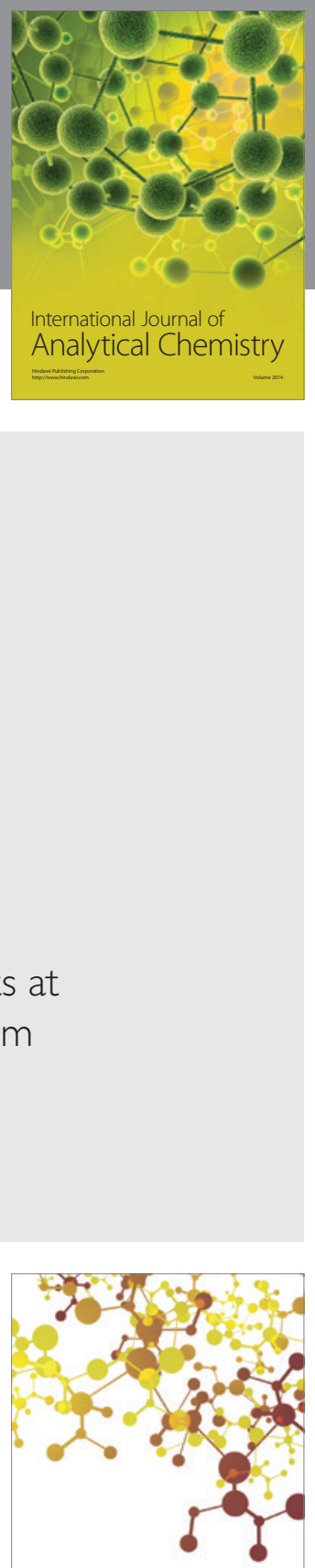

Journal of

Applied Chemistry
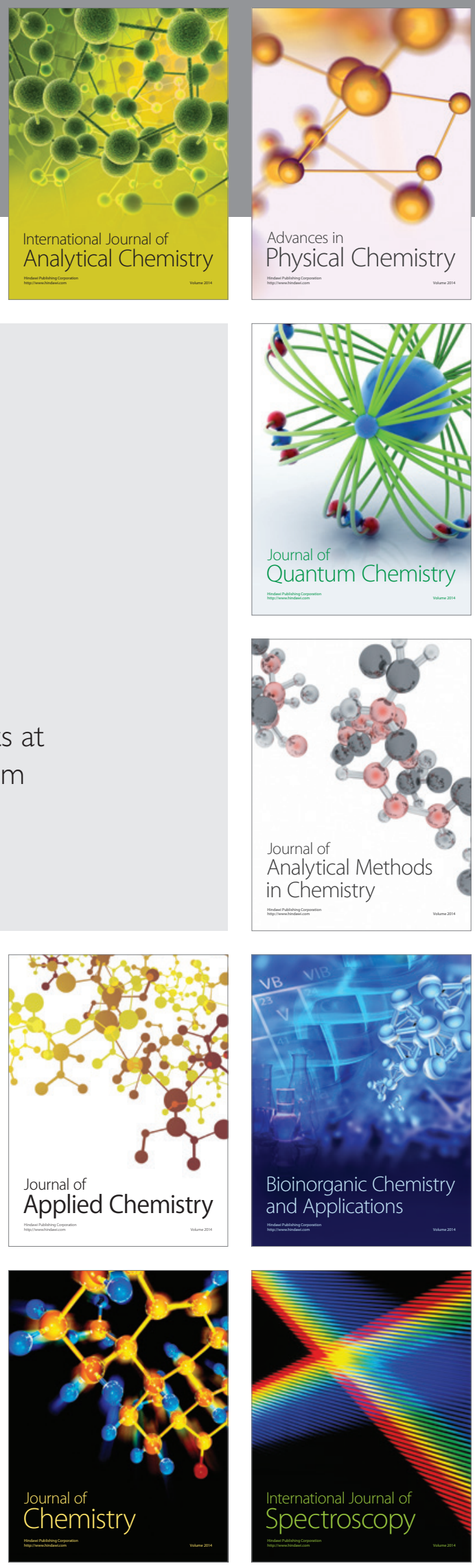